https://doi.org/10.22364/hssl.26.1.7

\title{
SOCIAL NETWORK MARKETING STRATEGY \\ THEORETICAL FRAMEWORK FOR A GREEN PHARMACEUTICAL COMPANY
}

\section{Dana Grossu}

M. sc. soc.

\section{Henrijs Kalıkis}

Dr. sc. admin.

\begin{abstract}
Nowadays, social network marketing has become a common strategy for local and global companies for many reasons, such as effectively communication with customers, building community of followers, increased brand awareness and brand recognition, and many others. The aim of the research is to develop social network marketing strategy theoretical framework for a green pharmaceutical company, based on theoretical research of marketing strategy development. In accordance to the research results, it has been decided to propose the development of perceived quality or brand-based advantage as the core strategy for value proposition for green pharmaceutical company`s social network marketing strategy framework. As a result, authors developed theoretical social network strategy framework that can serve as general action plan for green pharmaceutical companies.
\end{abstract}

Keywords: marketing, strategy, social network, framework, brand-based, pharmaceutical company

\section{Introduction}

For every company, including healthcare organisations and institutions, being the distinguishing, unique function of the business (Kotler et al., 2012), marketing has become the philosophy of management that recognises that the success of the enterprise is sustainable only if it can organise to meet the current and prospective needs of customers more effectively than competition (Doyle, 1998). Moreover, under the marketing concept, the paths to sales and profits are customer focus and value (Kotler \& Armstrong, 2001), thus, marketing tries to get the organisation to develop and offer what the customer will find of real value (Doyle \& Stern, 2006).

Nowadays, social network marketing has become a common strategy for local and global companies for many reasons such as effectively 
communication with customers, building community of followers, increased brand awareness and brand recognition, and many others.

Latvia has historically had a strong research, development, and manufacturing base in sophisticated chemical and pharmaceutical products. The industry is an important part of the Latvian economy, accounting for $7.5 \%$ of turnover for all manufacturing industries. Pharmaceuticals comprise the industry's largest sub-sector, creating $32 \%$ of its total turnover (Investment and Development Agency of Latvia, 2015). In Latvia, there are several green pharmaceutical companies in operation, including manufacturers of pharmaceuticals, vitamins and biologically active food supplements on the basis of natural components. The development of a new social network marketing strategy or improvement of the current ones would lead to increased brand value, brand awareness, and gaining the perceived value and brand-based competitive advantage, especially in green pharmaceutical business field.

The aim of the given research is to develop social network marketing strategy theoretical framework for a green pharmaceutical company, based on theoretical research of marketing strategy development.

To achieve the aim of the research the authors used the monographic research method that included literature review and theoretical analysis considering the social network marketing strategy development concepts.

\section{Results and Discussion}

The term marketing, both as a business unit and as a management process, is informed with a broad meaning. It covers several different fields, e.g., marketing research, strategic marketing, direct marketing, social media marketing, advertising and selling. For example, Kotler \& Armstrong (2001) suggest that a marketing concept takes off from the market definition, accentuates customer needs, coordinates all the customerrelated marketing activities, and generates profit by establishing long-term customer relationships based on customer satisfaction. Moreover, as far as the marketing concept is concerned, the way to sales and profits lies through customer focus and value (Kotler \& Armstrong, 2001). In some researches it can be found that tomorrow's sales and profits are ensured by today's satisfied customers, willing to stay loyal to the company (Doyle, 1998).

Defining specific marketing strategy and setting marketing plan is an essential part in building a company's competitive advantage and efficiency in the market. According to Aaker and McLoughlin (2010) findings, marketing strategy is a process of channelling a company's resources into optimal opportunities, the goals being the increase of sales and 
achievement of sustainable competitive advantage (Aaker \& McLoughlin, 2010). Kotler and Keller (2012) point out that "key ingredients of the marketing management process are insightful, creative strategies and plans that can guide marketing activities. Developing the right marketing strategy over the time requires a blend of discipline and flexibility. Firms must stick to a strategy but also constantly improve it. They must also develop strategies for a range of products and services within the organization" (Kotler \& Keller, 2012: 55).

It can be concluded that marketing strategy is not static, it is a process that should be constantly revised, reanalysed and adopted in accordance with the changes in internal and external environments. Yet, the marketing strategy is about positioning and gaining strong competitive advantage in the market to meet effectively the needs of the customers. In this connection, Winer and Dhar (2011) offer a scheme for a Complete Marketing Strategy Framework (see Figure 1).

Figure 1. A Complete Marketing Strategy

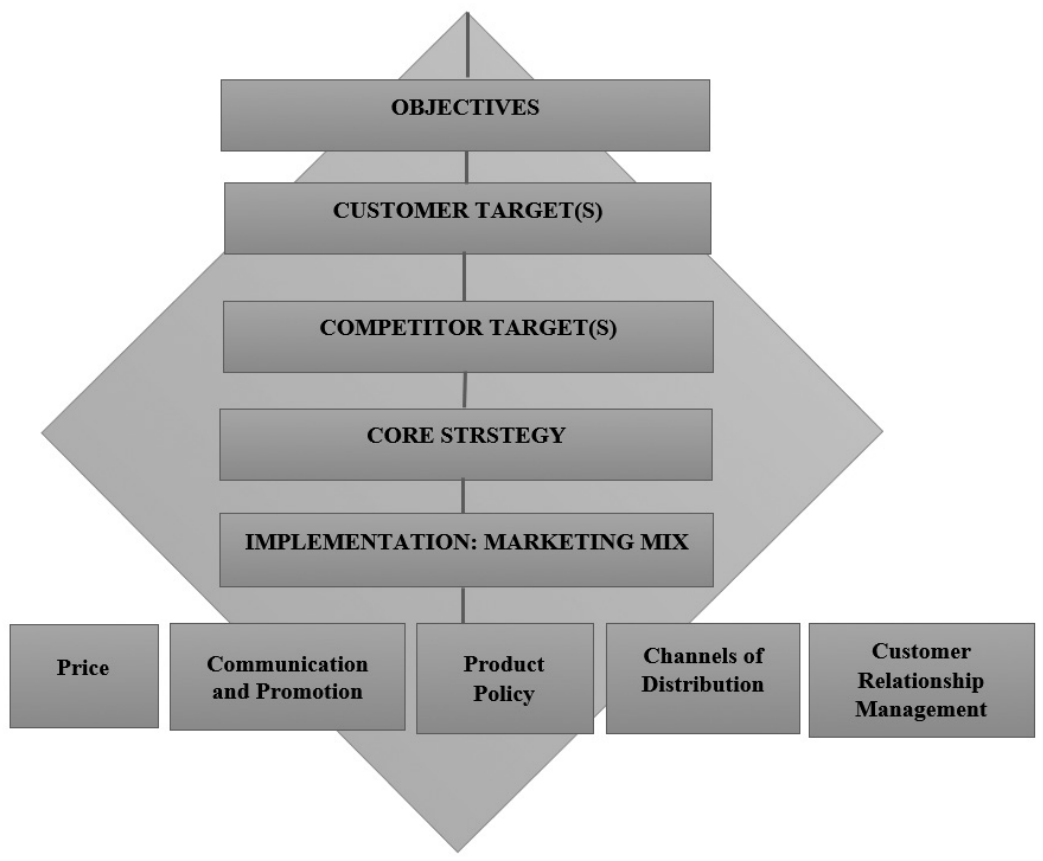

Source: Winer \& Dhar, 2011 
Analysing the Figure 1, the authors find the given Marketing Strategy Framework to be the most illustrative and consistent scheme for developing marketing strategy for a product or service that is suitable also for pharmaceutical companies. The authors agree with Winer and Dhar (2011), that one of the key components of the strategy is the value proposition, that will give the edge of uniqueness and creativity to the product or service, and serves as the basic mean how to differentiate company's product or service from the competitors.

Another study by Prymon (2014) encourages both large and small companies to incorporate the opportunity of gaining competitive advantage into their strategies, this opportunity stemming from the value for the customers. In the most general terms, contemporary sources of competitive advantage are defined through the generation of value in cooperation with stakeholders, predominantly consumers. It seems that strategies that are more specific can be developed on the basis of their value or values (Prymon, 2014). Furthermore, Winer and Dhar (2011) suggest that a value proposition should stem from the paramount strategic decision: the basis on which the company's product will be chosen by the customers over the competitors'. The term for this process is developing competitive or differential advantage. There are three general approaches to developing competitive advantage:

1) Cost- or price-based advantage. There are two ways of attaining a lowcost position in an industry or product category, i.e. economies of scale and experience curve. Economies of scale stipulate that, with larger sales, fixed costs of operations are spread over more units, with lower per unit costs. Experience curve implies that cumulative production or delivery of a service diminishes the costs, and thus, using the first period of a product's life as a yardstick, one can reliably predict the continued decline in costs.

2) Quality-based or differentiation advantage. An approach to achieving a competitive advantage by introducing an observable point of difference that customers will find valuable and worth paying for. There is an obvious tension between this approach and the lowcost-low-price competitive advantage, because this approach implies higher costs, even though with the concomitant increase in consumer's willingness to pay - and often higher margins.

3) Perceived quality or brand-based advantage. Many products and services stand out in the competitive environment by giving the customers the perception of higher overall quality or better on a particular product characteristic. Perceptual differential advantages are often applied to the products where differences are minor, hard to achieve or to sustain. 
Kotler et al. (2012) insist that the main outcome of marketing should be strategies that deliver customer perceived-value. According to them, market definitions of a business should come on top of product definitions. Rather than put forward its goods-producing process, a company should visualise its business activities as a customer-satisfying process aimed at delivering expected standards of customer-perceived value. Customer-perceived value positioning should lead to the formulation of a successful customerfocused value proposition, i.e. a cogent reason why the provider's product is the best option for the target customer.

Furthermore, Kotler et al. (2012) provide a definition of a successful brand, that is, "an identified product, service, person or place, augmented in such a way that the buyer or user perceives relevant unique, sustained added value that matches their needs most closely" (Kotler et al., 2012). Rosenbaum-Elliot, Percy and Pervan (2015) expand on the roles of the brand. The authors believe that all brands have a functional element, but most brands also need to create an emotional response, because an emotional association is much harder for competitors to duplicate and is, therefore, a more defendable position to hold. Kotler et al. (2012) justify the idea that consumers no longer buy the product or service for functional satisfaction, but their consumption becomes rather meaning based, and brands are often used as symbolic sources for the construction and maintenance of identity.

Another important aspect of branding is brand equity. Kotler et al. (2012) defined brand equity as the added value the brand endows a product or service. Winer and Dhar (2011) provide a more explicit definition of brand equity: "Brand equity is a set of assets (and liabilities) linked to a brand's name and symbol that adds to (or subtracts from) the value provided by a product or service to a firm or that firm's customers" (Winer \& Dhar, 2011). Furthermore, Winer and Dhar specify five categories of the assets and liabilities underlying brand value: Brand loyalty, Brand awareness, Perceived quality, Brand associations, Other brand assets, such as patents and trademarks (Winer \& Dhar, 2011).

The authors consider that the main dimension of brand's value is brand loyalty. As it is not only the repeat buying from current customers, which is also of a great importance, but also word of mouth of the loyal customers that is likely to generate new customers, as being reliable source of product information and perceived quality and value.

Yet, brand awareness is another important marketing concept. According to American Marketing Association, "it enables marketers to quantify levels and trends in consumer's knowledge and awareness of a brand's existence. At the aggregate (brand) level, it refers to the proportion of consumers who know of the brand" (American Marketing Association, 
2016). For this reason, Keller (1998) indicates that brand awareness can be characterised by depth and breadth, whereas the depth of awareness describes the likelihood that the brand can be recognised and recalled, and the breadth of brand awareness relates to the diversity of purchase and consumption situations in which the brand comes to the customer's mind. Moreover, Keller distinguish one more important source of brand equity that is brand image. He believes that in order to create a positive brand image, marketing programs should be employed that implant strong, unique, and favourable associations to the brand in the customer's memory. There are other ways of creating brand associations, apart from using marketing-controlled sources of information, e.g. through direct experience, other commercial and non-partisan sources (e.g., Consumer Reports), word of mouth, and by inferences due to the identification of the brand with a company, country, channel of distribution, person, place, or event.

More significantly, brand awareness has a great impact on creation of competitive advantage, or serve as the basic mean for elaborating strong competitive advantage. According to Aaker (2005), brand awareness highlights the recognition communicated onto a brand, conducive to the consumers' identification with brand product, which subsequently gives the company unchanged competitive advantage (Aaker, 2005).

The authors come to conclusion that brand is the way customers perceive the company. Following that idea, brand has meaningful function to the company's success - it helps to build strong market positioning. It also helps to differentiate the company in the market, and gain competitive advantage among other market offerings. Therefore, branding as such can be defined as a marketing strategy approach for differentiation and market positioning. Moreover, brand drives recognition of the company's product or service, which directly affects customer's purchase decision.

Nowadays almost every company, independently of its field of activities, has a social media profile or page, where the company shares its information, news, product or service special offers, discounts, etc. Hence, Social Network Marketing has become a common strategy for local and global companies for many reasons such as building strong community of followers, rise brand awareness or brand recognition, effectively communicate with customers, and many others. According to Scott (2011), "Social media provide the way people share ideas, content, thoughts, and relationships online. Social media differs from so-called mainstream media in that anyone can create, comment on, and add to social media content. Social media can take the form of text, audio, video, images and communities" (Scott, 2011). 
Scott also points out that social media should preferably be perceived not in terms of new technologies and tools, but rather in terms of the new opportunities, these technologies and tools offer to a provider for direct communication with the customers, in a place where they congregate right now. Moreover, Funk (2013) indicates that social media serves a channel for the following channels: customer service, customer engagement and brand-equity-building, and promotion and customer retention. He also suggests that the most useful framework for positioning in social media is (Funk, 2013):

1. To attract the potential customers, by standing out with a clear and unique brand.

2. To convert followers to buyers.

3. To transform, or to build a personal or emotional link with customers

Kotler et al. (2012) have pinpointed the difference between social media and social networking. According to them, social media are a group of internet-based applications that exploit the ideological and technological advantages of Web 2.0 and make provisions for the users to create and share self-generated content, while social networking is the grouping of individuals into specific groups, similar to small rural communities, mostly carried out online (Kotler et al., 2012). One type of social networking service is Facebook that contains directories of some categories, as well as the means to connect with friends. Facebook is a highly competitive and dynamic channel and is a powerful solution for most social media marketing strategies; most businesses would profit from turning it into the focal point of their efforts and promotions (Zarrella \& Zarrella, 2011). Because of its busy newsfeed, contributed content should be quickly digestible and easily recognisable. Moreover, the content should meet the standards of the unofficial pattern of a Facebook post. Each post should be specific to ones Facebook Page. Posts should be kept short and to the point. Media should be added to spice things up, it is important to specify what action one wants users to take. Facebook marketing can be amazingly cost-effective, especially versus traditional media alternatives, but it is fairly time-consuming. Facebook users appreciate two-way communication. They look for interesting and regularly updated content, and expect exclusive offers for being ones "friend". Facebook offers a wide range of tools and platforms to reach users. Marketers can leverage Facebook Ads, applications, Pages, or Events. An analytics system called Insights is integrated into each of the tools that provides reliable reports on activity levels and demographics (Zarrella \& Zarrella, 2011). All the above analysed led to the conclusion that nowadays social media marketing is a powerful tool, and each company should have an active social media presence. It helps to not only grow and develop company's brand, but to communicate 
with company's customers more directly and precisely in terms of target audience, in other words it helps to connect with consumers and build strong relationship. The authors conclude that social media marketing plays a vital role in increasing brand recognition and brand awareness, as social media network can be used as a channel for communicating company's competitive advantage with existing and new customers. In addition, social media strategy is cost- effective marketing tool, since it is easy implement, track and measure.

Following the theoretical analysis, the authors propose a social network marketing strategy framework for a green pharmaceutical company (see Figure 2). In building the strategy framework the authors considered two main objectives of the social network marketing strategy to be reached: increase brand loyalty and brand attachment, as well as to raise brand awareness. For the social network marketing strategy development, it is also important to evaluate current situation and the success of the current activities within a social network platform.

Figure 2. Social Network Marketing Strategy Framework for a Green Pharmaceutical Company

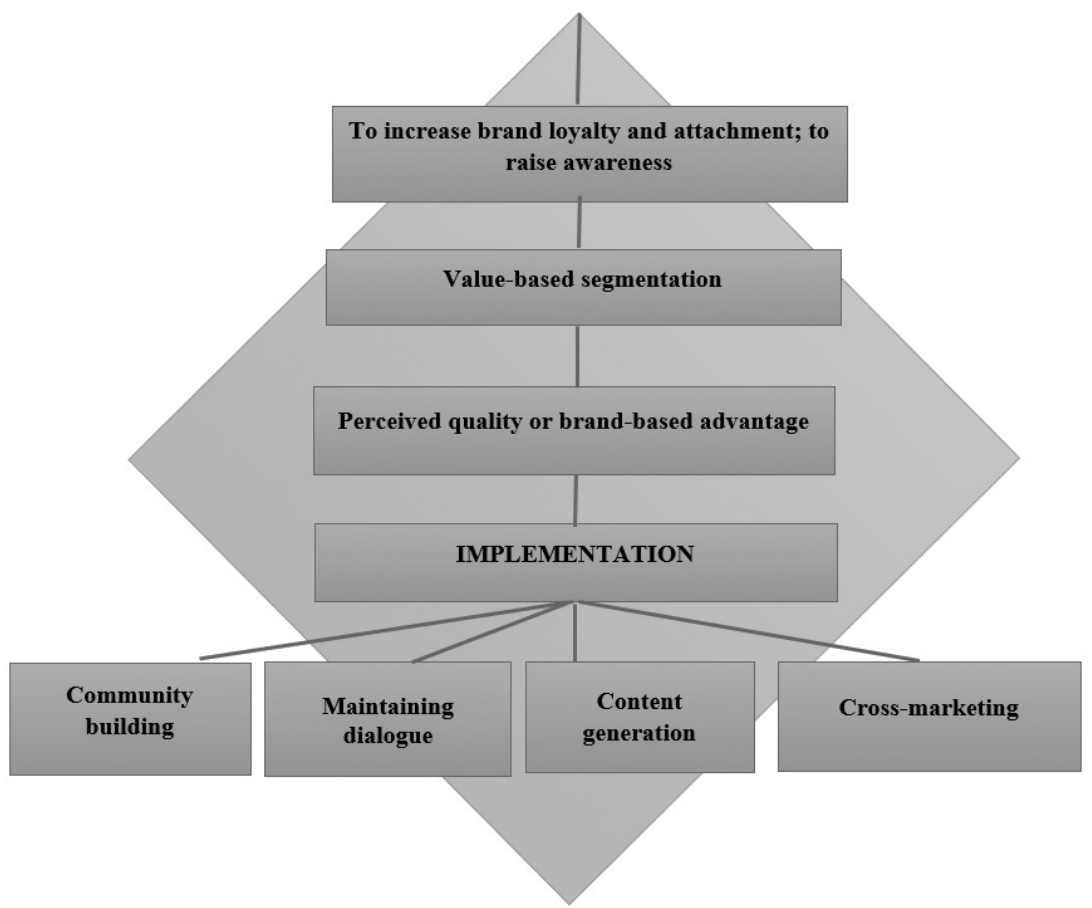

Source: Author's own illustration 
In the given framework, the authors propose step-by-step segments of marketing strategy:

1. To increase brand loyalty and brand awareness are the objectives to be reached by the social network marketing strategy.

2. Value-based segmentation is the customer targets, or the customers with specific criteria to be reached.

3. Perceived quality or brand-based advantage is the core strategy for value proposition that defines how the products are differentiated in the market, or the key reason why the customers should buy the company's products rather than a competing offering. The most important part of the core strategy is creating value proposition.

4. The implementation is the set of decisions about specific actions for social network marketing strategy.

The authors indicate that the perceived quality or brand-based advantaged is very essential that is also in accordance to Winer and Dhar (2011) research that perceived quality or brand-based advantage is the strategy to differentiate products from competitors by giving the customers the perception that they are of higher overall quality or better on particular characteristics.

The next task is to elaborate the value proposition and put it to work in the marketplace. This is called product positioning. Winer and Dhar (2011) suggest that positioning takes the competitive advantage (in the given case it is perceived quality or brand-based advantage) and plants it in the mind of the customers so that is understandable what the product stands for and how it is different from the competing offerings in the product category. It is important to mention that positioning includes both actual and perceived differential advantages. To develop value proposition or product positioning for perceived quality or brand-based advantage for a green pharmaceutical company, the authors suggest carrying out research with customers' questionnaires and find answers on:

1. Product feature improvement.

2. The customer's perception of a product quality and evaluation of the satisfaction of product need.

3. Evaluation of brand value and the relationship of the use of green pharmaceuticals and healthy lifestyle.

4. Brand logo associations.

Furthermore, Kotler and al. (2012) emphasise that the main task of marketing is to develop strategies that deliver customer perceived-value. Thus, it is essential to use exactly those features and association that can be determined during the research, as they define the function of products, which satisfies product need, therefore presents benefit of the purchasing. 
The implementation segment of social network marketing strategy framework offers the ways, or the set of activities in its broad meaning on how to achieve the objectives of the social network marketing strategy for a green pharmaceutical company.

After elaborating the value proposition based on the features and associations defined, the community building approach could be used to raise brand awareness among potential customers.

The second main activity included into the set of implementation tasks in order to reach the objectives of the strategy is dialogue maintaining. The company should keep in touch with the target audience on the consistent basis; the social network is a great platform for communication with company's target audience, as people are easily reach through the mean of social network.

The most important part of the strategy implementation is content generation, or the types of the content included into the social network marketing activities. The authors have identified the following content generation aspects for green pharmaceutical companies:

1. Transparency content providing information on how the production works, where the raw materials are grown, making emphasis on high technologies and highly professional employees, which would positively influence on the brand value and build the trust between the company and customers.

2. Educational or informative content on the contribution of the use of green pharmaceutical products to healthy lifestyle.

3. Content describing the minimum or zero hazard effect of the use of green pharmaceutical products on the child organism.

4. Content describing the unique features of the green pharmaceutical products and the superior overall quality, as for example, the notion of "green" product and its correlation with sustainable product.

5. Content using symbol positive emotional effect that makes the brand not only memorable, but also influences brand attachment, loyalty, recognition, and awareness.

6. Content that gets customers involved. For example, the social network is a great platform where the company can ask for customers' opinion. Involved them into conversation, ask whether the products satisfy product need, are their expectations of a product met. The customers should feel that the company care about their experience with the products and listening to their concerns.

7. Content showing that green pharmaceutical company label is more than just a brand, for example, it could be emphasising the brand as a symbol of local production, or as the part of healthy lifestyle. 
The authors consider that such content directly influence perceived brand value, thus increasing brand awareness and brand attachment.

8. Content expressing company's appreciation to the customers, for example, company say thank you to the customers, or wishing them happy holidays. Following the theoretical background, the positive emotional post-purchase perception is very important in building brand loyalty and attachment strategy.

As suggested previously, content generation is the most essential part of the social network marketing strategy, thus content generation phase should be more specifically and detailed elaborated within the marketing plan. The authors conclude that the approach described is only general recommendations, long-term action plan, or strategy framework for developing marketing campaign for a green pharmaceutical company.

\section{Conclusion}

Based on theoretical analysis, the contemporary marketing strategy involves marketing research, analysis of the results, and the development of marketing strategy framework. The authors developed a social network marketing strategy framework stages consist of setting the objectives to be reached by the strategy, identifying customer targets, core strategy formulation including value proposition for market positioning, and the implementation of the strategy, or the action plan how to reach the objectives set at the beginning of the framework. The authors emphasise that the developed theoretical social network strategy framework for a green pharmaceutical company is a general action plan or a "road map" to more detailed marketing plan. Research that is more detailed will be carried out to test if the developed theoretical framework is suitable in real green pharmaceutical company business environment.

\section{REFERENCES}

1. Aaker, D. A., 2005. Strategic Market Management. $1^{\text {st }}$ ed. New York: John Wiley \& Sons.

2. Aaker, D. A. \& McLoughlin, D., 2010. Strategic Market Management Global Perspectives. $1^{\text {st }}$ ed. West Sussex: John Wiley \& Sons Ltd.

3. American Marketing Association, 2016. Available at: https://www.ama.org/resources/ pages/dictionary.aspx?dLetter $=B$ [Accessed: $25^{\text {th }}$ of November, 2016].

4. Available at: http://www.mckinsey.com/business-functions/marketing-and-sales/ our-insights/the-consumer-decision-journey, [accessed $25^{\text {th }}$ of October, 2016].

5. Doyle, P., 1998. Marketing Management and Strategy. $2^{\text {nd }}$ ed. Harlow: Prentice Hall. 
6. Doyle, P. \& Stern, P., 2006. Marketing Management and Strategy. $4^{\text {th }}$ ed. Essex: Pearson Education Limited.

7. Funk, T., 2013. Advanced Social Media Marketing: How to Lead, Launch, and Manage a Successful Social Media Program, Apress.

8. Investment and Development Agency of Latvia, 2015. Chemical, Pharmaceutical and Biotechnological Industry in LATVIA. Available at: http://www.liaa.gov.lv/files/ liaa/attachments/chemical_pharmaceutical_biotechnological_industry_min_0.pdf, [accessed: $5^{\text {th }}$ of March, 2018].

9. Kotler, P. \& Armstrong, G., 2001. Principles of Marketing. $9^{\text {th }}$ ed. New Jersey: Prentice Hall.

10. Kotler, P. et al., 2012. Marketing Management. $2^{\text {nd }}$ ed. Essex: Pearson Education Limited.

11. Kotler, P., Armstrong, G., Saunders, J. \& Wong, V., 1999. Principles of Marketing. $2^{\text {nd }}$ ed. New Jersey: Prentice Hall Europe.

12. Kotler, P. \& Keller, K. L., 2012. Marketing Management. $14^{\text {th }}$ ed. Essex: Pearson.

13. Prymon, M., 2014. Marketing Strategies for Enterprises in Services Market. Journal of International Scientific Publications, 8(118/120), pp. 53-145.

14. Scott, D. M., 2011. The New Rules of Marketing \& PR. $3^{\text {rd }}$ ed. New Jersey: John Wiley \& Sons.

15. Winer, R. \& Dhar, R., 2011. Marketing Management. $4^{\text {th }}$ ed. New Jersey: Prentice Hall.

16. Zarrella, D. \& Zarrella, A., 2011. The Facebook Marketing Book. $1^{\text {st }}$ ed. Sebastopol: O’Reilly Media. 